\title{
Brown bear communication hubs: patterns and correlates of tree rubbing and pedal marking at a long-term marking site
}

\author{
Eloy Revilla ${ }^{\text {Corresp., } 1}$, Damián Ramos Fernández ${ }^{2}$, Alberto Fernández-Gil ${ }^{1}$, Agnieszka Sergiel ${ }^{3}$, Nuria Selva ${ }^{3}$, Javier \\ Naves $^{1}$ \\ 1 Department of Conservation Biology, Estación Biológica de Doñana CSIC, Seville, Spain \\ 2 Consejería de Infraestructuras, Ordenación del Territorio y Medio Ambiente, Gobierno del Principado de Asturias, Oviedo, Spain \\ 3 Institute of Nature Conservation, Polish Academy of Sciences, Krakow, Poland \\ Corresponding Author: Eloy Revilla \\ Email address: revilla@ebd.csic.es
}

Chemical communication is important for many species of mammals. Male brown bears, Ursus arctos, mark trees with a secretion from glands located on their back. The recent discovery of pedal glands and pedal-marking at a site used for tree-rubbing led us to hypothesize that both types of marking form part of a more complex communication system. We describe the patterns of chemical communication used by different age and sex classes, including differences in the roles of these classes as information providers or receivers over four years at a long-term marking site. Using video recordings from a camera trap, we registered a total of 285 bear-visits and 419 behavioral events associated with chemical communication. Bears visited the site more frequently during the mating season, during which communication behaviors were more frequent. A typical visit by male bears consisted of sniffing the depressions where animals pedal mark, performing pedalmarking, sniffing the tree, and, finally, rubbing against the trunk of the tree. Adult males performed most pedal- and tree-marking ( $95 \%$ and $66 \%$ of the cases, respectively). Males pedal-marked and tree-rubbed in $81 \%$ and $48 \%$ of their visits and sniffed the pedal marks and the tree in $23 \%$ and $59 \%$ of visits, respectively. Adult females never pedal marked, and juveniles did so at very low frequencies. Females rubbed against the tree in just $9 \%$ of their visits; they sniffed the tree and the pedal marks in $51 \%$ and $21 \%$ of their visits, respectively. All sex and age classes performed pedal- and tree-sniffing. There were significant associations between behaviors indicating that different behaviors tended to occur during the same visit and were more likely if another individual had recently visited. These associations leading to repeated marking of the site can promote the establishment of long-term marking sites. Marking sites defined by trees and the trails leading to them seem to act as communication hubs that brown bears use to share and obtain important information at population level. 


\section{Brown bear communication hubs: patterns and}

3 correlates of tree rubbing and pedal marking at a long-

4 term marking site

5

6

8

Eloy Revilla ${ }^{1}$, Damián Ramos Fernández ${ }^{2}$, Alberto Fernández-Gil ${ }^{1}$, Agnieszka Sergiel ${ }^{3}$, Nuria Selva $^{3} \&$ Javier Naves ${ }^{1}$

${ }^{1}$ Department of Conservation Biology, Estación Biológica de Doñana CSIC, Calle Américo Vespucio 26, 41092 Sevilla, Spain

${ }^{2}$ Consejería de Infraestructuras, Ordenación del Territorio y Medio Ambiente, Gobierno del Principado de Asturias, C/Coronel Aranda, 2 - Planta 3a , 33005 Oviedo, Spain

${ }^{3}$ Institute of Nature Conservation, Polish Academy of Sciences, Mickiewicza Av. 33, 31120 Krakow, Poland.

Corresponding Author:

Eloy Revilla ${ }^{1}$

${ }^{1}$ Department of Conservation Biology, Estación Biológica de Doñana CSIC, Calle Américo Vespucio 26, 41092 Sevilla, Spain Email address: revilla@ebd.csic.es

\section{ABSTRACT}

Chemical communication is important for many species of mammals. Male brown bears, Ursus arctos, mark trees with a secretion from glands located on their back. The recent discovery of pedal glands and pedal-marking at a site used for tree-rubbing led us to hypothesize that both types of marking form part of a more complex communication system. We describe the patterns of chemical communication used by different age and sex classes, including differences in the roles of these classes as information providers or receivers over four years at a long-term marking site. Using video recordings from a camera trap, we registered a total of 285 bear-visits and 419 behavioral events associated with chemical communication. Bears visited the site more frequently during the mating season, during which communication behaviors were more frequent. A typical visit by male bears consisted of sniffing the depressions where animals pedal mark, performing pedal-marking, sniffing the tree, and, finally, rubbing against the trunk of the tree. Adult males performed most pedal- and tree-marking ( $95 \%$ and $66 \%$ of the cases, respectively). Males pedalmarked and tree-rubbed in $81 \%$ and $48 \%$ of their visits and sniffed the pedal marks and the tree in $23 \%$ and $59 \%$ of visits, respectively. Adult females never pedal marked, and juveniles did so at very low frequencies. Females rubbed against the tree in just $9 \%$ of their visits; they sniffed the 
46

47

tree and the pedal marks in $51 \%$ and $21 \%$ of their visits, respectively. All sex and age classes performed pedal- and tree-sniffing. There were significant associations between behaviors indicating that different behaviors tended to occur during the same visit and were more likely if another individual had recently visited. These associations leading to repeated marking of the site can promote the establishment of long-term marking sites. Marking sites defined by trees and the trails leading to them seem to act as communication hubs that brown bears use to share and obtain important information at population level.

\section{INTRODUCTION}

Marking behavior is essential in the mediation of chemical communication and social interactions in mammals (Potts \& Penn 2002; Johansson \& Jones, 2007). The chemical signals left at specific sites provide long-lasting messages in the absence of the signal provider (White, Swaisgood \& Zhang, 2002; Scordato, Dubay \& Drea, 2007). In carnivores, the function of scent marks has been associated with territorial defense (Wronski et al., 2006), intra-sexual competition (Gosling \& Roberts, 2001), and the defense of trophic resources (Piñeiro \& Barja, 2015). Scent marking is particularly important for solitary species ranging widely in large home ranges (Begg et al., 2003; Vogt et al., 2014). These species must rely on an effective communication system that maximizes the transfer of information at low cost in order to maintain their social organization by advertising to mates and competitors (Allen, Yovovich \& Wilmers, 2016).

Urine and feces are a relatively inexpensive means of scent marking used by many carnivore species at the expense of relatively low efficiency in the transfer of information (Vogt et al., 2016). More specialized chemical compounds may provide detailed information on the individual, including their sex and reproductive status (Alberts, 1992). They are produced by specialized holocrine, apocrine and/or eccrine skin glands, often located in the anal, subcaudal, interdigital skin, and chin areas, among others. To be effective, their secretions should persist in the environment for long periods to maximize the probability of reaching potential receivers (Swaisgood et al., 2004). Additionally, individuals scent mark specific sites, such as territorial borders, and prominent locations that are often revisited by them and other individuals, including dens, food sources and busy trails (Sillero-Zuburi \& Macdonald, 1998; Revilla \& Palomares, 2002; King et al., 2017). Chemical cues guide receiving individuals to investigate, ignore, counter and/or over-mark previous marks (Laidre \& Johnstone, 2013). The presence of long-lasting marks of multiple individuals in a marking area may promote the synergy between different types of signals, potentially eliciting several communication-related behaviors (Sumpter \& Brännström, 2008). These complexities make some particular types of marking sites especially important in the regulation of social behavior. The repeated use by multiple individuals for long periods of time convert these marking sites into communication hubs at a population level (King et al., 2017).

Ursids are non-territorial animals that move over large areas with low contact rates between individuals (Martin et al., 2013). In spite of this, they maintain a complex network of social interactions in which information on the presence of other individuals is critical (Støen et al., 2005; Steyaert et al., 2012). Chemical communication plays an important role in the maintenance of bear 
social organization (Noyce \& Grarshelis, 2014). Brown bears Ursus arctos mark conspicuous objects such as trees, rocks or even poles, with secretions from the sebaceous glands and possibly also the apocrine glands located in the skin of their back (Tomiyasu et al., 2018), and, in some cases, with claw and bite marks as well (Nie et al., 2012; Clapham et al., 2013; Taylor, Allen \& Gunther, 2015).

Bipedal back-rubbing against trees has been widely described as the most common marking behavior of brown bears across its Holarctic range, showing seasonal and sex and age variations in marking frequency (Green \& Mattson, 2003; Clapham et al., 2012, 2013; Sato et al., 2014; Seryodkin, 2014; Spassov et al., 2015; Tattoni et al., 2015). Additionally, pedal-marking has recently been reported as an important marking behavior (Taylor et al., 2015; Sergiel et al., 2017). Typical deep marks left in the ground by brown bears, possibly during pedal-marking, were described long ago as leading towards bear trees (LeFranc et al., 1987). The presence of pedal scent glands in brown bears and their significance in communication have also been recently described (Sergiel et al., 2017). Nevertheless, pedal-marking has yet to be characterized in terms of its phenology, the sex and age class of the individuals and other environmental correlates, as well as its connection with tree marking, given that they seem to simultaneously occur at the same sites (Clapham et al., 2014; Sergiel et al., 2017).

In this paper we hypothesize that pedal-marking and tree-rubbing are deeply linked in brown bears, forming a more complex communication system than previously recognized. We expect to find differences in the use of marking sites by different sex and age classes of individuals, depending on their primary role as either information providers or receivers. Specifically, we made use of a multi-year dataset on chemical communication by brown bears at a marking site in a wellknown population living in the Cantabrian Mountains, northern Spain. The site is known to have been intensively used for pedal-marking and tree-rubbing by bears since 2002, when it was already well stablished, and has therefore been used by more than a generation (see Sergiel et al., 2017 for a basic description of pedal marking at this site). Specifically, we aimed at (1) assessing the frequency of main marking behaviors by brown bears of different age and sex classes; (2) identifying associations among behaviors as well as among signal providers (the ones marking) and receivers (the ones sniffing the marks), and (3) determine the role of other factors, such as climatic variables, in the occurrence of marking behaviors. Finally, we discuss the significance of these communication hubs intensively used by brown bears for long periods of time.

\section{MATERIALS \& METHODS}

\section{Study site}

The study was conducted in the western half of the Cantabrian Range (NW Spain), a mountain system inhabited by a brown bear population which currently numbers around 230 individuals, with a density of 1.6 individuals $/ 100 \mathrm{~km}^{2}$ (Pérez et al., 2014). The study area is located in Fuentes del Narcea, Degaña e Ibias Natural Park (Cangas del Narcea, Asturias). Our study site is located in an area with high quality habitat for brown bears (Naves et al., 2003), including denning and 
119 mating areas, areas used by females with cubs, and also vegetation offering plenty of resources

120

121

122

123

124

125

126

127

128

129

130

131

132

133

134

135

136

137

138

139

140

141

142

143

144

145

146

147

148

149

150

151

152

153

154

155

156

157

158

used during hyperphagia, when bears feed continuously in preparation for hibernation.

In this area, there are multiple sites used by brown bears for chemical communication. These sites can be easily identified by the presence of a tree, pole or rock that is used for rubbing, often in association with a series of pedal marking tracks leading to the vertical structure that is marked. We selected one site for continuous monitoring on the basis of the evidence of repeated use by brown bears for pedal-marking for more than a decade (Sergiel et al., 2017). As the Cantabrian brown bear population is threatened, we do not provide the exact location of the site due to conservation concerns. The first evidence of ground pedal-marking at this site was obtained in 2002 during an opportunistic observation by one of the authors (DR) of an adult male during the mating season. The site is characterized by an oak tree (Quercus petraea) heavily used by brown bears for rubbing, and by conspicuous marks in the ground made by the bears' repeated use of the same spots for pedal-marking (a total of 48 marks made by bears' feet are evident to the human eye).

\section{Sampling protocol}

Data were collected by DR at the selected site during long-term monitoring for conservation and management. The Principado de Asturias-Consejería de Agroganadería y Recursos Autóctonos granted data access, and DR was authorised to participate by exp-no. 2016/033072, Principado de Asturias-Consejería de Hacienda y sector Público. An automatic camera trap (Bushnell Trophy digital camera trap \#19466 with motion triggered day/night recording) was set up between January 2012 and January 2016, during which time it was working almost continuously. Initially, between January 2012 and April 2012, the device was placed laterally in a low position from which the tree marked by brown bears was visible. Data obtained during these first four months were not used in the analyses. After this initial sampling, the camera trap was mounted in a zenith position (directly above the site) at a height of six meters on the main trunk of the marked tree to obtain a standardized field of view and to reduce direct interference with bears and other animals. The field of view of the camera trap covered an area of about $100 \mathrm{~m}^{2}$. The camera trap was programmed to shoot one-minute videos, with a 10 -second interval between consecutive videos. We considered a visit event as the group of videos that are not more than 20 minutes apart. This time window was selected following visual inspection of the plot of the cumulative proportion of videos sorted by the time to the next video (Fig. S1). For comparative purposes, we also used a 20-minute time interval to define visit events for other species. Note that a visit can include more than one individual bear, as occurs in the case of females with cubs or males and females moving together during the mating season. The weather data were obtained from the nearby automatic station of Leitariegos, belonging to the Spanish Agencia Estatal de Meteorología (AEMET).

\section{Individuals and communication behaviors}

In the Cantabrian Mountains, the steep slopes and low forest cover make it relatively easy to observe brown bears, especially during spring and summer. Individuals present in valleys are 
159

160

161

162

163

164

165

166

167

168

169

170

171

172

173

174

175

176

177

178

179

180

181

182

183

184

185

186

187

188

189

190

191

192

193

194

195

196

197

198

detected by scanning the area with spotting scopes from vantage points. This method is used to obtain annual counts of the number of females with cubs of the year and as a long-term method to census this population (Wiegand et al., 1998). As a result, some of the individuals moving in the study area are known, especially when they have some identifying marks, and are thus easily distinguished from other individuals. The professional technicians doing those censuses are experts in recognizing the sex and age of individuals by specific traits under good observation conditions. We classified the recorded individuals into the following sex and age categories: 1) adult males, identified by the combination of large size, and neck and head shape; 2) adult females, when accompanied by cubs, or identified by their size, head and neck shapes, and explicit behavior in the presence of other individuals, often adult males in the mating season; 3) cubs, individuals in their first year or in their second year until May and always accompanied by their mother; 4) juveniles, independent individuals in their second year of life from June onwards and in their third year, clearly smaller in size than adults and usually accompanied by siblings; and, 5) undetermined sex and age class, which included the remaining individuals.

In the case of adult males, some individuals were identified by comparison with known animals observed in repeated sightings at other sites in the study area. These individuals were characterized by a combination of body size, head shape, coat color patterns and especially the very characteristic light-colored permanent markings, normally present on their necks (see description of individualized bears in Supplementary Material). The Cantabrian brown bear population is characterized by its small size and the large variability shown by individuals in coat color and the common presence of markings especially on their necks (Clevenger \& Purroy 1991). In other cases, we were able to temporarily classify some individuals in an age and sex class or even identify them during shorter periods of time because they were associated with other bears in seasonal or yearly groups such as mating pairs, females with dependent cubs, and groups of independent juveniles repeatedly seen in the area. Females are more difficult to identify individually on a permanent basis. We used the number of accompanying cubs to establish a minimum number of females visiting the site each year. We did not attempt to identify other types of individuals such as independent juveniles and cubs.

We classified the behaviors displayed by brown bears in the videos into the following types: 1) sniffing pedal marks, when an individual stops or slows its pace and puts its nose to the pedal marks on the ground; 2) pedal-marking, performed by a walking bear with the particular gait of twisting its fore and hind feet on the ground in specific depressions repeatedly used by that individual and other bears during previous visits; 3) tree-sniffing, when an individual calmly puts its nose to the trunk of the rubbing tree; 4) tree-rubbing, when a bear vigorously rubs its back, neck or shoulders against the trunk of the tree while standing on its hind legs; and, 5) other behaviors, in which a bear usually walks in and out of the field of vision. In the videos recorded at the study site we did not detect any clear instance of scratching the tree (clawing; Taylor et al., 2015). For each visit event we determined if each type of behavior was performed (presence/absence of the behavior, not the number of times) by each bear in the available sequence of videos.

PeerJ reviewing PDF | (2018:11:32708:3:0:NEW 23 Oct 2020) 
199

200

201

202

203

204

205

206

207

208

209

210

211

212

213

214

215

216

217

218

219

220

221

222

223

224

225

226

227

228

229

230

231

232

233

234

235

236

237

238

\section{Analyses}

First, we described the overall use of the site and the behaviors performed by the visiting brown bears over time and by age and sex classes. Then, we analyzed which variables were associated with the observed patterns (Table 1). We hypothesized that the probability that bears visited the marking site in a given day and performed one of the behaviors in each visit was affected by not only the time elapsed since the previous visit by a bear, but also the season, distinguishing between mating season (April, May and June) and non-mating season (other months), as well as the age and sex class of the focal individuals, and, in the analyses where it made biological sense, by the weather conditions that occurred between visit events affecting the duration of the chemical signals. We performed Generalized Linear Mixed Models (GLMMs) on the response variables (occurrence of the specific behaviors) using a binomial error distribution and year as a random factor. As some individuals were repeatedly observed, there could be some pseudoreplication problem. Solving this issue is not easy as a fraction of the observations correspond to unknown animals. Nevertheless, and in order to check if pseudoreplication was an issue, we repeated the analyses of the selected models adding individual ID as an additional random factor (unidentified individuals were grouped under a single individual label; results are shown in the supplementary materials). Models were run with the potential combination of biologically meaningful explanatory variables within each group of response variables (Table 1). To reduce the effect of multicolinearity, when two predictors were correlated, we selected the one with a stronger association with the dependent variable. From the resulting models, we report and interpret only those within $\triangle \mathrm{AIC}<2$. We computed the marginal and conditional $\mathrm{R}^{2}$ for each selected model (Nakagawa \& Schielzeth 2013). For inference we used a cut-off level of $P<0.10$. Analyses were performed in $R$ vs3.3.3 with lme4 (v1.1-19; Bates et al. 2015) and MuMIn (v1.43.6; Bartoń 2019) packages.

\section{RESULTS}

In total, the camera trap was active for 1,174 days (April 2012 to December 2015), with an average temporal coverage of $83 \%$ of the possible days per month (Fig 1, Table S1). It registered 329 videos with bear presence; representing 224 visit events and a total of 285 bear-visit events (note that more than one individual can be present during the same visit event). Brown bears were the most common visitors (42\%), with more than five visits per month on average (Fig S2, Table S2). The visitation rate of other species was considerably lower despite being more abundant in most cases (Fig S2). Among brown bears, adult males were the most frequent visitors with 132 bear visits ( $46 \%$ of total bear visits, Table 2 ). The rest of the visits were performed by adult females in 57 cases $(20 \%)$, cubs in $44(15 \%)$, juveniles in $23(8 \%)$ and individuals of undetermined age and sex in 29 (10\%; Table 2). The visits followed a bimodal diel pattern with maxima around dawn and dusk (Kaczensky et al. 2006) but occurred also throughout the day and into the night (24-h rhythm, Fig S3). Bears visited the marking site more frequently during the mating season (AprilJune; Fig 1, on average $26.3 \%$ of the days sampled per month had bears visiting the site during the 
239

240

241

242

243

244

245

246

247

248

249

250

251

252

253

254

255

256

257

258

259

260

261

262

263

264

265

266

267

268

269

270

271

272

273

274

275

276

277

mating season, versus $14.1 \%$ during the rest of the year excluding the hibernation period (January and February); Table 3; Table S3). The probability that the site was visited by bears on a given day was negatively associated with the time since the last visit of a male (the shorter the lapse, the higher the probability; Table 3; Table S3).

\section{Communication behaviors}

The typical sequence of a visit consists of a bear approaching the tree following the path where it can sniff the depressions in which animals pedal mark, performing pedal-marking itself, stopping at the tree, sniffing it, and, finally, rubbing against the trunk (see video in Supplementary materials). This sequence can vary with different combinations of behaviors and in different orders, and some parts of the sequence can be repeated. On one occasion, a male also rubbed its body against pedal marks. There was no apparent communication behavior in $22 \%$ of the visits, although some could have occurred out of the field of view of the camera trap.

Out of a total of 482 recorded behaviors, the majority corresponded with some form of chemical communication (87\%). Communication behaviors occurred in most months except January and February (hibernation period; Table S4). Sniffing of pedal marks was less frequent $(58,12 \%)$ than pedal-marking $(113,23 \%)$; while tree-sniffing (153 cases, $31 \%)$ was more frequent than tree-rubbing $(96,20 \%$; Table S4).

The communication behaviors displayed by bears varied greatly among age and sex classes. All sex and age classes performed pedal- and tree-sniffing. Individuals identified as adult males performed most of the pedal-marking (107 cases, 95\%) and, to a lesser extent, tree-rubbing (63 cases, 66\%, Fig 2). Interestingly, adult females did not perform pedal-marking, while juveniles did so at very low frequency (Fig 2). Tree-rubbing was performed by all age and sex classes, but at higher frequencies by males (Fig 2).

Males and females sniffed the pedal marks in $23 \%$ and $21 \%$ of their visits, respectively; while cubs, juveniles and undetermined bears did so in $61 \%, 48 \%$ and $26 \%$ of their visits, respectively. The probability that a bear sniffed the pedal marks during a visit was higher outside the mating season (Table 3). Also, the lower the average precipitation and the average temperature in the preceding days, the higher the probability of sniffing the pedal marks (Table 3, Tables S3, S8). Finally, the probability of sniffing the pedal marks tended to be negatively related to the time elapsed since the last time a bear performed pedal-marking at the site (Table 3; Tables S3, S8).

Males performed pedal-marking in $81 \%$ of their visits to the site. They both pedal-marked and sniffed the pedal marks in $20 \%$ of their visits. Juveniles and undetermined bears performed pedal-marking in $17 \%$ and $7 \%$ of their visits, respectively, while females and cubs never pedal marked. The probability of performing pedal-marking by male bears visiting the site was positively associated with tree-rubbing by the same individual and negatively with the time elapsed since the previous visit of a bear that pedal-marked at the site (the shorter the time, the higher the probability of pedal-marking, Table 3; Tables S3, S8). The association of pedal-marking probability with the remaining factors was weaker (Table S3). 
278

279

280

281

282

283

284

285

286

287

288

289

290

291

292

293

294

295

296

297

298

299

300

301

302

303

304

305

306

307

308

309

310

311

312

313

314

315

316

317

Males sniffed the tree in $59 \%$ of their visits, while adult females did so in $51 \%$ of their visits. Cubs, juveniles, and undetermined individuals showed interest in the tree, sniffing it in $61 \%$, $48 \%$, and $26 \%$ of their visits, respectively. Interestingly, the probability of sniffing the tree by a visiting bear was higher the longer the time elapsed since the previous tree-marking event and negatively related to the precipitation during that period (Table 3; Tables S3, S8), and was not affected by the sex or age class of the individual. Nevertheless, the model was not very explanatory (Table 3).

Males performed tree-rubbing in $48 \%$ of their visits. They engaged in both pedal-marking and tree-rubbing during the same visit on $43 \%$ of their visits and tree-rubbing and tree-sniffing in $35 \%$ of their visits. Adult females rubbed against the tree in just $9 \%$ of their visits. Juveniles, cubs and undetermined individuals tree-rubbed on $39 \%, 34 \%$ and $14 \%$ of occasions, respectively. Adult males and juveniles had higher probabilities of tree-rubbing during their visits than females (Table 3; Table S3, S8). The probability that a bear performed tree-rubbing during a visit was positively associated with tree-sniffing and pedal-marking by the same individual (Table 3; Tables S3, S8), and tended to be positively associated with the time since the previous tree-rubbing event (Table 3; Tables S3, S8).

Several recognizable individuals visited the site repeatedly (Supplementary Material), some of them throughout the study period. Four adult males visited the site between 10 and 35 times during the study, with up to 15 visits in one year (M1 to M4, Table S6). These males were frequent markers; for example, M2 and M3 were responsible for most of the instances of pedalmarking (59\%, Table S7), while M2 was the bear that most frequently displayed tree-rubbing behavior (43\%, Table S7). Additionally, other males visited the site sporadically (Table S9). These additional males were known individuals that were repeatedly observed near the study site (at least four additional males in 2012, five in 2013 and 2015, and seven in 2014). A minimum of one female visited the site in 2013 and 2015, two in 2014 and three in 2012. The minimum number of different individual bears visiting the site per year ranged between 11 in 2013 and 18 in 2015 (Table S9).

\section{DISCUSSION}

In this work we show that the chemical communication behavior of brown bears at tree-rubbing sites is more complex than previously recognized, with pedal-marking being an integral part of this communication system. These marking sites form communication hubs where multiple individuals share and receive important information at the population level (Sergiel et al. 2018). Tree-rubbing is a well-known scent-marking behavior performed by bears (Green \& Mattson, 2003; Clapham et al., 2012; Sato et al., 2014; Seryodkin, 2014; Tattoni et al., 2015; Lamb et al., 2017). Brown bears vigorously rub their flanks and back against the tree to scent mark it with secretions from the glands located on their back (Tomiyasu et al., 2018). They also mark other types of objects in the same way, especially in areas where the availability of trees is low (Seryodkin 2014). Our results, in accordance with published information, show that tree rubbing can be performed by any class of individual at any time, but it is clearly monopolized by adult

Peer] reviewing PDF | (2018:11:32708:3:0:NEW 23 Oct 2020) 
318 males, especially during the mating season (see also Clapham et al., 2012; Lamb et al., 2017). 319 Additionally, our results indicate that the information is received by all types of individuals 320 irrespective of their age or sex.

321

322

323

324

325

326

327

328

329

330

331

332

333

334

335

336

337

338

339

340

341

342

343

344

345

346

347

348

349

350

351

352

353

354

355

356

357

Interestingly, tree-marking does not occur in isolation. Pedal-marking by males occurs as part of the marking process in association with tree-rubbing. As with tree-rubbing, pedal-marking is performed by males with a higher frequency during the mating season, while all classes of individuals act as receivers of the information. The existence of deep footprint marks forming one or more trails in the ground leading towards trees has been known for a long time, though not examined in detail (e.g., LeFranc et al., 1987; Clapham et al., 2013; Seryodkin 2014). Additionally, the typical behavioral sequence performed by males during pedal-marking has also been described with a variety of names, including bear dance, sumo walking, cowboy walk or stomping (Sergiel et al., 2017), but has been often interpreted as part of a stereotyped behavior leading to marking the tree and not a marking in itself. The recent description of pedal glands in the feet of bears and the concomitant pedal-marking (Sergiel et al., 2017) together with our results on the relationship between both pedal- and tree-marking provide new insights into scent-marking system in brown bears.

The data used in our description have some shortcomings that need to be considered. We provide data from only one site, although for a long period of nearly continuous monitoring. The area covered by the camera trap recorded only part of the area and, therefore, we may have missed behaviors, such as pedal-marking or sniffing when animals were out of the field of view; or treemarking when the bears used other trees (there were nearby trees also used for marking). We could only detect sniffing behaviors when they were apparent in the videos, whereas bears have a very efficient olfactory system that might allow them to detect markings with little effort. Additionally, the zenith position of the camera trap may have limited our capacity to detect other potential marking behaviors such as urination or more complex stereotyped behaviors associated with treerubbing (Clapham et al., 2014). Despite these limitations, we believe that our results are relevant to the interpretation of chemical communication at marking sites by brown bears.

\section{Sending and receiving information}

The importance of chemical communication at the site varied as a function of the individuals, depending on their sex, age, and presumably other conditions such as dominance or breeding status. Nearly half of the visits to the marking site were made by animals identified as adult males. They were responsible for most pedal-marking, and, to a lesser extent, tree-rubbing behaviors. Both behaviors were strongly associated when performed by adult males. Some males visited the site very often while others were more sporadic. Interestingly, some males marked in most of their visits while others mostly acted as information receivers. This may reflect a structure of dominance in the males sharing the area. Females, on the other hand, never pedal-marked and rarely rubbed the tree, and neither did the cubs accompanying their mothers. Young animals (of unknown sex) showed an intermediate pattern between males and females. Tree-rubbing was more frequently displayed by bears which also sniffed the tree and performed pedal-marking and positively related 
358

359

360

361

362

363

364

365

366

367

368

369

370

371

372

373

374

375

376

377

378

379

380

381

382

383

384

385

386

387

388

389

390

391

392

393

394

395

396

397

with the time elapsed since a previous tree-rubbing event, typically describing the behavioral sequence of visiting males. Male brown bears have seasonally enlarged sebaceous glands on their back and prominent eccrine, apocrine and sebaceous glands in their feet; glands that are more active during the mating season, in association with their increased testosterone levels (Sergiel et al., 2017; Tomiyasu et al., 2018). Therefore, males acted as main sources of chemical messages at the site, as has been shown in other study areas (Clapham et al., 2014; Lamb et al., 2017).

Sniffing behavior, especially that of ground marks, is less obvious and therefore more likely to go unnoticed in videos. Nevertheless, all types of individuals showed interest in the chemical marks, acting as genuine information receivers. The probability of sniffing the marks during a visit was affected by weather conditions, with higher temperatures and precipitation in the preceding days reducing the probability of sniffing ground marks, a pattern that was not associated with actual pedal-marking, and higher precipitation negatively affecting tree-sniffing. The diluting effects of precipitation and temperature on the volatility of the odorous molecules left by bears at the marking site are a possible interpretation of these results. Interestingly, the probability of sniffing the tree was higher the longer the time elapsed since the previous visit, while it was the opposite for ground sniffing, suggesting a differential detectability between the chemical compounds secreted by pedal and back glands and among different substrates.

\section{Why brown bears visit these sites}

Brown bears use chemical marking to convey information from senders to receivers. Why they do this and what type of information is transferred is still a matter of discussion. The chemical profiles of pedal and shoulder secretions indicate that they contain information on at least the sex and reproductive status of the individual (Sergiel et al., 2017; Tomiyasu et al., 2018). Additionally, it would not be surprising if information on the actual individual is also provided, as seems to occur with secretions from anal sacs (Rosell et al., 2011; Jojola et al., 2012). In species that normally exhibit a solitary non-territorial use of space, knowing the individuals whom they may encounter is quite valuable. Several non-exclusive hypotheses have been proposed to explain scent-marking in brown bears: self-advertisement for mate attraction, communication of individual dominance, competitor assessment and infanticide avoidance, with different roles depending on bear density (Clapham et al., 2012; Lamb et al., 2017). Our results show that chemical communication in brown bears is complex. Males are the main senders and also the main receivers, with some of them marking a lot while others tend to mostly receive information, indicating communication of individual dominance and the ability to assess male competitors. Male bears mark all year round but with a main peak during the mating season, a period of intense competition. This pattern has also been found at rubbing trees, both natural and artificially created to collect bear hairs (i.e. tree hair traps), in different ecosystems (Green \& Mattson 2003, Karamanlidis et al. 2010, Sato et al. 2014, Berezowska-Cnota et al. 2017, Lamb et al. 2017).

Females seem to visit the site less often, but all year round, and when they do, they are especially interested in receiving information. Knowing which males are moving around and their social dominance is very important for females in mate selection, since mating with the more

Peer) reviewing PDF | (2018:11:32708:3:0:NEW 23 Oct 2020) 
398

399

400

401

402

403

404

405

406

407

408

409

410

411

412

413

414

415

416

417

418

419

420

421

422

423

424

425

426

427

428

429

430

431

432

433

434

435

436

437

dominant males that are present all year round would minimize the overall risk of infanticide to their litters. Additionally, females with cubs of the year may benefit from knowing if a new male enters the area (Bellemain et al., 2006). Although more rarely, females, juveniles and cubs also rub trees, but it is unclear why they do it. In the case of juveniles learning by imitation may be the main reason (Clapham et al., 2014). Given that the sebaceous secretion in the shoulder of males is linked to testosterone levels, the secretion of females, cubs and juveniles can be expected to be testimonial or simply non-existent. If that is the case, their tree-rubbing may serve the purpose of masking their odor with that of adult males roaming the area. The resulting increase in chemical similarity could help to reduce the risk of infanticide by scent-matching (Gosling \& McKay, 1990). If this interpretation is correct, tree-rubbing would have a scent-marking purpose only for males, while helping females and cubs to obtain a chemical camouflage by scent-rubbing as well as transitionally being part of the learning process of juveniles. In summary, there is no single best hypothesis to explain the role of these communication hubs, with the most plausible being a complex combination of dominance, mate selection, competitor assessment, mate selection and infanticide avoidance.

\section{Brown bear communication hubs}

Undoubtedly, sites like the one we monitored are important for brown bears at the population level. Our results show that the tree and the trails leading to it form a communication hub that most bears living in the area use to share and obtain information. Bears were the most frequent visitors to our site despite the easy accessibility and the fact that bears are not the most common large mammal. Bears choose specific trees in places that are well situated for the passage of other individuals (Green \& Mattson 2003; Sato et al., 2014). At these sites there is an association between different communication behaviors, with marking behaviors triggering the subsequent sniffing and marking of later visitors (Berezowska-Cnota et al. 2017). Nevertheless, these sites are not uncommon. In the vicinity of our site there were other trees used repeatedly by bears for marking (see Supplementary video). Brown bears maintain a dense system of marking sites that allow for a complex communication network over large spatial scales. Although they are not easy for humans to locate, several authors report varying densities of marking sites depending on bear density, including 0.26 sites $/ \mathrm{km}^{2}$ in the Italian Alps, 0.4 sites $/ \mathrm{km}^{2}$ in Hokkaido, Japan, $1.4 \mathrm{sites} / \mathrm{km}^{2}$ in the Russian Komi Republic, 20 sites $/ \mathrm{km}^{2}$ in British Columbia, and 27 sites $/ \mathrm{km}^{2}$ in the Valley of Geysers on Kamchatka Peninsula (Lloyd, 1979; Sato et al., 2014; Seryodkin, 2014; Tattoni et al., 2015). Many of these studies describe trails evidencing pedal-marking (e.g., Clapman et al., 2013; Seryodkin, 2014). There are open questions that remain to be answered, such as the heterogeneity in the use of the multiple marking sites available to brown bears within their home ranges or the variability in marking intensity within and across populations.

\section{CONCLUSIONS}

We showed that pedal-marking and tree-rubbing are strongly associated in a complex chemical communication system. At our site, bears visited more frequently during the mating season.

Peer) reviewing PDF | (2018:11:32708:3:0:NEW 23 Oct 2020) 
438 More dominant male bears typically sniffed the depressions where animals pedal marked,

439

440

441

442

443

444

445

446

447

448

449

450

451

452

453

454

455

456

457

458

459

460

461

462

463

464

465

466

467

468

469

470

471

472

473

474

475

476

477

performed pedal-marking, sniffed the tree, and rubbed against the trunk. Adult males monopolized pedal- and tree-marking. Adult females, on the other hand, never pedal marked, and juveniles rarely did so. Females acted more as information receivers, rarely rubbing the tree. All sex and age classes performed pedal- and tree-sniffing, thus obtaining information on previous visitors. Different behaviors tended to occur during the same visit and were more likely if another individual had recently visited, generating long-term marking sites. These sites act as communication hubs that brown bears use to share and obtain important information on the animals present over a wide area at the population level. The intensive use of these sites and their number and density provide an idea of the importance of this communication system for this wide ranging, non-social large carnivore, with a complex mating system.

\section{ACKNOWLEDGEMENTS}

We want to thank Aquila M. Pérez 'Kiti' for her help and support during the field work and Miguel Delibes for his help in the initial design of the study and his support during the analyses and writing.

\section{REFERENCES}

Alberts, A.C. (1992). Constraints on the design of the chemical communication systems in terrestrial vertebrates. Am. Nat. 139, S62-S89. DOI: $10.1086 / 285305$

Allen, M.L., Wallace, C.F. \& Wilmers, C.C. (2015). Patterns in bobcat (Lynx rufus) scent marking and communication behaviors. J. Ethol. 33, 9-14. DOI: 10.1007/s10164-014-04180

Allen, M.L., Yovovich, V.\& Wilmers, C.C. (2016). Evaluating the response of a territorial solitary carnivore to potential mates and competitors. Sci. Rep. 6, 27257. DOI: $10.1038 /$ srep27257

Bartoń, K. (2019). MuMIn: Multi-Model Inference. https://CRAN.Rproject.org/package=MuMIn

Bates, D., Maechler, M., Bolker, B., Walker, S. (2015). Fitting Linear Mixed-Effects Models Using lme4. J. Stat. Softw. 67(1), 1-48. doi:10.18637/jss.v067.i01

Begg, C.M., Begg, K.S., Du Toit, J.T. \& Mills, M.B.L. (2003). Scent-marking behaviour of the honey badger, Mellivora capensis (Mustelidae), in the southern Kalahari. Anim. Behav. 66, 917-929. DOI: 10.1006/anbe.2003.2223

Bellemain, E., Zedrosser, A., Manel, S., Waits, L.P., Taberlet, P. \& Swenson, J.E. (2006). The dilemma of female mate selection in the brown bear, a species with sexually selected infanticide. Proc. R Soc. Lond B Biol. Sci. 273, 283-291. DOI: 10.1098/rspb.2005.3331

Berezowska-Cnota, T., Luque-Márquez, I., Elguero-Claramunt, I., Bojarska, K., Okarma, H. \& Selva, N. (2017). Effectiveness of different types of hair traps for brown bear research and monitoring. PloS ONE 12, p.e0186605. DOI: 10.1371/journal.pone.0186605 
478 Clapham, M., Nevin, O.T., Ramsey, A.D. \& Rosell, F. (2012). A hypothetico-deductive

479

480

481

482

483

484

485

486

487

488

489

490

491

492

493

494

495

496

497

498

499

500

501

502

503

504

505

506

507

508

509

510

511

512

513

514

515

516 approach to assessing the social function of chemical signaling in a non-territorial solitary carnivore. PLoS ONE 7, e35404. DOI: 10.1371/journal.pone.0035404

Clapham, M., Nevin, O.T., Ramsey, A.D. \& Rosell, F. (2013). The function of strategic tree selectivity in the chemical signaling of brown bears. Anim. Behav. 85, 1351-1357. DOI: 10.1016/j.anbehav.2013.03.026

Clapham, M., Nevin, O.T., Ramsey, A.D. \& Rosell, F. (2014). Scent-marking investment and motor patterns are affected by the age and sex of wild brown bears. Anim. Behav. 94, 107116. DOI: 10.1016/j.anbehav.2014.05.017

Clevenger, A. P., \& Purroy, F. J. (1991). Ecología del oso pardo en España (Vol. 4). Museo Nacional de Ciencias Naturales, Consejo Superior de Investigaciones Científicas, Madrid. $160 \mathrm{pp}$

Gosling, L.M, \& McKay H.V. (1990). Scent-rubbing and status signalling by male mammals. Chemoecology 1, 92-95. DOI: 10.1007/BF01241649

Gosling, L.M. \& Roberts, S.C. (2001). Scent-marking by male mammals: Cheat-proof signals to competitors and mates. In: Advances in the Study of Behavior 30. Slater, P.J.B., Rosenblatt, J.S., Snowdon, C.T. \& Roper, T.J. (Eds.). London: Academic Press, pp. 169-217.

Green, G.I. \& Mattson, D.J. (2003). Tree rubbing by Yellowstone grizzly bears Ursus arctos. Wildl. Biol. 9, 1-9. DOI: 10.2981/wlb.2003.002

Johansson, B.G. \& Jones, T.M. (2007). The role of chemical communication in mate choice. Biol. Rev. 82, 265-289. DOI: 10.1111/j.1469-185X.2007.00009.x

Jojola, S.M., Rosell, F., Warrington, I., Swenson, J.E. \& Zedrosser, A. (2012). Subadult brown bears (Ursus arctos) discriminate between unfamiliar adult male and female anal gland secretion. Mamm. Biol. 77, 363-368. DOI: 10.1016/j.mambio.2012.05.003

Kaczensky, P., Huber, D., Knauer, F., Roth, H., Wagner, A., Kusak, J. (2006). Activity patterns of brown bears (Ursus arctos) in Slovenia and Croatia. J. Zool. 269, 474-485.

King, T.W., Salom-Pérez, R., Shipley, L.A., Quigley, H.B., \& Thornton, D.H. (2017). Ocelot latrines: communication centers for Neotropical mammals. J. Mamm. 98, 106-113. DOI: 10.1093/jmammal/gyw174

Laidre, M.E. \& Johnstone, R.A. (2013). Animal signals. Curr. Biol. 23, 829-833. DOI: 10.1016/j.cub.2013.07.070

Lamb, C.T., Mowat, G., Gilbert, S.L., McLellan, B.N., Nielsen, S.E. \& Boutin, S. (2017). Density-dependent signaling: An alternative hypothesis on the function of chemical signaling in a non-territorial solitary carnivore. PLoS ONE 12, e0184176. DOI: 10.1371/journal.pone.0184176

LeFranc Jr, M.N., Moss, M.B., Patnode, K.A., \& Sugg III, W.C. (1987). Grizzly bear compendium. Washington, DC: Interagency Grizzly Bear Committee. 540pp Lloyd, K.A. (1979). Aspects of the ecology gf black and grizzly bears in coastal British Columbia. M.s. Thesis, Univ. of B.C. Vancouver. 150 pp. 
517 Martin, J., Moorter, B., Revilla, E., Blanchard, P., Dray, S., Quenette, P. Y., Allainé, D., \& 518 Swenson, J.E. (2013). Reciprocal modulation of internal and external factors determines 519 individual movements. J. Anim. Ecol. 82, 290-300. DOI: 10.1111/j.1365-2656.2012.02038.x

520

521

522

523

524

525

526

527

528

529

530

531

532

533

534

535

536

537

538

539

540

541

542

543

544

545

546

547

548

549

550

551

552

553

554

555

Nakagawa, S., Schielzeth, H. (2013). A general and simple method for obtaining R2 from generalized linear mixed-effects models. Methods Ecol. Evol. 4,133-142. DOI: 10.1111/j.2041-210x.2012.

00261.x.

Naves, J., Wiegand, T., Revilla, E. \& Delibes, M. (2003). Endangered species constrained by natural and human factors: the case of brown bears in Northern Spain. Cons. Biol. 17, 12761289. DOI: $10.1046 / j .1523-1739.2003 .02144 . x$

Nie, Y., Swaisgood, R.R., Zhang, Z., Hu, Y., Ma, Y. \& Wei, F. (2012). Giant panda scentmarking strategies in the wild: role of season, sex and marking surface. Anim. Behav., 84, 39-44. DOI: 10.1016/j.anbehav.2012.03.026

Noyce, K.V. \& Garshelis, D.L. (2014). Follow the leader: social cues help guide landscape-level movements of American black bears (Ursus americanus). Can. J. Zool. 92, 1005-1017. DOI: 10.1139/cjz-2014-0029

Pérez T., Naves, J., Vázquez, J.F., Fernández-Gil, A., Seijas, J., Albornoz, J., Revilla, E., Delibes, M. \& Domínguez, A. (2014) Estimating the population size of the endangered Cantabrian brown bear through genetic sampling. Wild. Biol. 20,300-309. DOI: 10.2981/wlb.00069

Revilla, E. \& Palomares, F. (2002). Spatial organization, group living and ecological correlates in low-density populations of Eurasian badgers, Meles meles. J. Anim. Ecol. 71, 497-512. DOI: $10.1046 / j .1365-2656.2002 .00617 . x$

Rodgers, T.W., Giacalone J., Heske, E.J., Pawlikowski, N.C., \& Schooley, R.L. (2015). Communal latrines act as potentially important communication centers in ocelots Leopardus pardalis. Mamm. Biol., 80,380-384 DOI: 10.1016/j.mambio.2015.05.004.

Rosell, F., Jojola, S.M., Ingdal, K., Lassen, B.A., Swenson, J.E., Arnemo, J.M. \& Zedrosser, A. (2011). Brown bears possess anal sacs and secretions may code for sex. J. Zool., 283, 143152. DOI: $10.1111 / \mathrm{j} .1469-7998.2010 .00754 . \mathrm{x}$

Sato, Y, Kamiishi, C., Tokaji, T., Mori, M., Koizumi, S., Kobayashi, K., Itoh, T., Sonohara, W., Takada, M.B. \& Urata, T. (2014). Selection of rub trees by brown bears (Ursus arctos) in Hokkaido, Japan. Acta Theriol. 59, 129-137. DOI: 10.1007/s13364-013-0143-z

Scordato, E.S., Dubay, G. \& Drea, C.M. (2007). Chemical composition of scent marks in the ringtailed lemur(Lemur catta): glandular differences, seasonal variation, and individual signatures. Chem. Senses 32, 493-504. DOI: 10.1093/chemse/bjm018

Sergiel, A., Naves, J., Kujawski, P., Maślak, R., Serwa, E., Ramos, D., Fernández-Gil, A., Revilla, E., Zwijacz-Kozica, T., Zięba, F., Painer, J. \& Selva N. (2017). Histological, chemical and behavioural evidence of pedal communication in brown bears. Sci. Rep. 7 , 1052. DOI: $10.1038 / \mathrm{s} 41598-017-01136-1$

PeerJ reviewing PDF | (2018:11:32708:3:0:NEW 23 Oct 2020) 
556 Seryodkin, I.V. (2014). Marking activity of the Kamchatka brown bear (Ursus arctos piscator).

557

558

559

560

561

562

563

564

565

566

567

568

569

570

571

572

573

574

575

576

577

578

579

580

581

582

583

584

585

586

587

588

589

590

591

592

593

594

595 Achiev. Life Sci. 8, 153-161. DOI: 10.1016/j.als.2015.04.006

Sillero-Zubiri, C. \& Macdonald, D.W. (1998). Scent-marking and territorial behaviour of Ethiopian wolves Canis simensis. J. Zool., 245, 351-361.

Spassov, N., Spiridonov, G., Ivanov, V., Assenov, L. (2015). Signs of the bear life activities and their utilization for the monitoring of the brown bear (Ursus arctos L.) in Bulgaria. Historia Naturalis Bulgarica 22, 73-83.

Steyaert, S.M., Endrestøl, A., Hacklaender, K., Swenson, J.E. \& Zedrosser, A. (2012). The mating system of the brown bear Ursus arctos. Mammal Rev., 42, 12-34. DOI: 10.1111/j.1365-2907.2011.00184.x

Støen, O.G., Bellemain, E., Sæbø, S. \& Swenson, J.E. (2005). Kin-related spatial structure in brown bears Ursus arctos. Behav. Ecol. Sociobiol., 59, 191-197. DOI: 10.1007/s00265-0050024-9

Sumpter, D.J.T. \& Brännström, Å. (2008). Synergy in social communication. In: Sociobiology of Communication. d'Ettorre, P., Hughes, D. P. (Eds.). Oxford: Oxford University Press.

Swaisgood, R.R., Lindburg, D.G., White, A.M., Zhang, H. \& Zhou, X. (2004). Chemical communication in giant pandas: experimentation and application. In: Giant pandas: biology and conservation. Lindburg, D.G. \& Baronga, K. (Eds.). University of California Press.

Tattoni, C., Bragalanti, N., Groff, C. \& Rovero, F. (2015). Patterns in the use of rub trees by the Eurasian brown bear. Hystrix 26, 118-124. DOI: 10.4404/hystrix-26.2-11414

Taylor, A.P., Allen, M.L. \& Gunther, M.S. (2015). Black bear marking behavior at rub trees during the breeding season in northern California. Behaviour 152, 1097-1111. DOI: 10.1163/1568539X-00003270

Tomiyasu, J., Yanagawa, Y., Sato, Y., Shimozuru, M., Nagano, M., Sasaki, M., Sakamoto, H., Matsumoto, N., Kobayashi, K., Kayano, M. \& Haneda, S. (2018). Testosterone-related and seasonal changes in sebaceous glands in the back skin of adult male brown bears (Ursus arctos). Can. J. Zool., 96, 205-211. DOI: 10.1139/cjz-2017-0028

Vogt, K., Hofer, E., Ryser, A., Kölliker, M. \& Breitenmoser, U. (2016). Is there a trade-off between scent marking and hunting behaviour in a stalking predator, the Eurasian lynx, Lynx lynx?. Anim. Behav., 117, 59-68. DOI: 10.1016/j.anbehav.2016.04.004

Vogt, K., Zimmerman, F., Kolliker, M. \& Breitenmoser, U. (2014). Scent-marking behaviour and social dynamics in a wild population of Eurasian lynx Lynx lynx. Behav. Process. 106, 98-106. DOI: 10.1016/j.beproc.2014.04.017

White, A.M., Swaisgood, R.R. \& Zhang, H. (2002). The highs and lows of chemical communication in giant pandas (Ailuropoda melanoleuca): effect of scent deposition height on signal discrimination. Behav. Ecol. Sociobiol. 51, 519-529. DOI: 10.1007/s00265-0020473-3

Wiegand, T., Naves, J., Stephan, T. \& Fernandez-Gil, A. (1998). Assessing the risk of extinction for the brown bear (Ursus arctos) in the Cordillera Cantabrica, Spain. Ecological Monographs, 68, 539-570.

Peer) reviewing PDF | (2018:11:32708:3:0:NEW 23 Oct 2020) 
596 Wronski, T., Apio, A., Baranga, J. \& Plath, M. (2006). Scent marking and territorial defence in 597 male bushbuck (Tragelaphus scriptus). J. Zool. 270, 49-56. DOI: 10.1111/j.1469-

$598 \quad$ 7998.2006.00109.x

599

600 
601 Figure 1. Monthly distribution of brown bear visits to the marking site. The average number

602 of individual visits per day of sampling (left axis, indicating the total number and those identified

603 as males) and the sampling effort (right axis), measured as the proportion of days that the camera 604 trap was active every month (x-axis) between April 2012 and December 2015. See Table S1 in 605 Supplementary material for numerical data.

606

607 Figure 2. Proportion of the different behaviors. Proportion of all observed behaviors

608 performed by age and sex classes (panels A and B) and per month (panels C and D). Proportions 609 were calculated as the number of observations within each class divided by the total number of 610 observations of all behaviors in all size classes. Data in Tables S4 and S5.

611

612

613 


\section{Table $\mathbf{1}$ (on next page)}

Description of response and explanatory variables used in the analyses

All response variables were binary: occurrence of visit or visits in a given day for day visit or occurrence within a visit for communication behaviors. The variables listed were the ones explored in each model (marked with $X$ ). Not all combinations were explored due to biological sense (weather variables were used only for sniffing behaviors because weather can affect the amount of time that marks last, or due to the most common logical sequence of events, from sniff pedal marks into tree rubbing), or to the structure of the data (day visit has no individual descriptors as in a given day more than one individual can occur; pedal marking can only be analysed for males because they were the only ones using this marking). 
Table 1. Description of response and explanatory variables used in the analyses. All response variables were binary: occurrence of visit or visits in a given day for day visit or occurrence within a visit for communication behaviors. The variables listed were the ones explored in each model (marked with $X$ ). Not all combinations were explored due to biological sense (weather variables were used only for sniffing behaviors because weather can affect the amount of time that marks last, or due to the most common logical sequence of events, from sniff pedal marks into tree rubbing), or to the structure of the data (day visit has no individual descriptors as in a given day more than one individual can occur; pedal marking can only be analysed for males because they were the only ones 7 using this marking).

Explanatory variables

\begin{tabular}{|c|c|c|c|c|c|c|}
\hline \multicolumn{2}{|r|}{ Explanatory varıables } & \multicolumn{5}{|c|}{ Response variables } \\
\hline Label & Description & $\begin{array}{l}\text { day } \\
\text { visit }\end{array}$ & $\begin{array}{l}\text { sniff pedal } \\
\text { markst }\end{array}$ & $\begin{array}{l}\text { pedal } \\
\text { marking* }\end{array}$ & $\begin{array}{l}\text { sniff } \\
\text { tree } t\end{array}$ & $\begin{array}{l}\text { tree } \\
\text { rubbingt }\end{array}$ \\
\hline \multicolumn{7}{|c|}{ Individual variables } \\
\hline age_sex & $\begin{array}{l}\text { age-sex class of the bear (Male, Female, Juvenile, } \\
\text { Undetermined) }\end{array}$ & & $X$ & & $X$ & $X$ \\
\hline age_sex_tree & $\begin{array}{l}\text { age-sex class of the previous bear marking the tree (Male, } \\
\text { Female, Juvenile, Undetermined) }\end{array}$ & & & & $X$ & \\
\hline \multicolumn{7}{|c|}{ Temporal variables } \\
\hline days & $\begin{array}{l}\text { time since the previous visit of a bear (in days, common } \\
\text { logarithm) }\end{array}$ & & $X$ & $X$ & $X$ & $X$ \\
\hline days_male & $\begin{array}{l}\text { time since the previous visit of a male (in days, common } \\
\text { logarithm) }\end{array}$ & $X$ & & & & \\
\hline days_pedal & $\begin{array}{l}\text { time since the previous visit of a bear pedal marking (in days, } \\
\text { common logarithm) }\end{array}$ & $X$ & $X$ & $X$ & & \\
\hline days_tree & $\begin{array}{l}\text { time since the previous visit of a bear rubbing the tree (in days, } \\
\text { common logarithm) }\end{array}$ & $X$ & & & $X$ & $X$ \\
\hline \multicolumn{7}{|c|}{ Weather variables } \\
\hline Prec_pedal & $\begin{array}{l}\text { average precipitation of the days elapsed since the previous } \\
\text { bear visit that performed pedal marking }(\mathrm{mm})\end{array}$ & & $X$ & & & \\
\hline Prec_tree & $\begin{array}{l}\text { average precipitation of days elapsed since the previous bear } \\
\text { visit that performed tree marking }(\mathrm{mm})\end{array}$ & & & & $X$ & \\
\hline Temp_pedal & $\begin{array}{l}\text { average temperature of the days elapsed since the previous bear } \\
\text { visit that performed pedal marking }\left({ }^{\circ} \mathrm{C}\right)\end{array}$ & & $X$ & & & \\
\hline Temp_tree & $\begin{array}{l}\text { average temperature of the days elapsed since the previous bear } \\
\text { visit that performed tree rubbing }\left({ }^{\circ} \mathrm{C}\right)\end{array}$ & & & & $X$ & \\
\hline
\end{tabular}


Behavioral variables

pedal_marking pedal marking performed by the same bear visit

season season: mating (April, May, June) vs non-mating (other months)

$\begin{array}{lllll} & & & & X \\ & X & X & X\end{array}$

sniff_pedal

sniff pedal marks during the bear visit

$X$

sniff_tree

sniff tree during the bear visit

$X$

tree_rubbing tree-rubbing during the same bear visit

$X$

8 *only for males

9 †all bears except cubs 


\section{Table 2 (on next page)}

Number of behaviours displayed by different age and sex classes

Data recorded by the camera trap at the marking site between 2012 and 2015. 
1 Table 2. Number of behaviors displayed by different age and sex classes. Data recorded by

2 the camera trap at the marking site between 2012 and 2015.

Age-Sex classes

\begin{tabular}{lcccccc}
\hline Behavior & Males & Females & Cubs & Juveniles & Undetermined & Total \\
\hline Sniffing pedal marks & 30 & 12 & 3 & 9 & 4 & 58 \\
Pedal-marking & 107 & 0 & 0 & 4 & 2 & 113 \\
Sniffing tree & 78 & 29 & 27 & 11 & 8 & 153 \\
Tree-rubbing & 63 & 5 & 15 & 9 & 4 & 96 \\
Other & 5 & 20 & 12 & 7 & 18 & 62 \\
\hline Total number of behaviors & 283 & 66 & 57 & 40 & 36 & 482 \\
Total number of visits & 132 & 57 & 44 & 23 & 29 & 285 \\
\hline
\end{tabular}

3 


\section{Table 3 (on next page)}

Estimates of the effect of the factors included in the best models

Models were GLMMs with binomial distribution and year as random factor (Table S7 in Supplementary material). The models on pedal marking were run only on males and the rest with all types of individuals except for cubs. Note that, for the tree rubbing model, the estimates of the age_sex parameters correspond with the comparison of those classes with females, which is the reference class (as defined by the intercept of the model). See Table 1 for a description of the variables. 
1 Table 3. Estimates of the effect of the factors included in the best models. Models were

2 GLMMs with binomial distribution and year as random factor (Table S7 in Supplementary

3 material). The models on pedal marking were run only on males and the rest with all types of

4 individuals except for cubs. Note that, for the tree rubbing model, the estimates of the age_sex

5 parameters correspond with the comparison of those classes with females, which is the reference

6 class (as defined by the intercept of the model). See Table 1 for a description of the variables.

\begin{tabular}{|c|c|c|c|}
\hline Model & Estimate & SE & $p$ \\
\hline \multicolumn{4}{|c|}{ bear visit (all classes of individuals) } \\
\hline (intercept) & 0.859 & 0.267 & 0.001 \\
\hline days_male & -1.823 & 0.196 & $<0.0001$ \\
\hline season & -0.379 & 0.177 & 0.032 \\
\hline \multicolumn{4}{|l|}{$\mathrm{R}^{2}($ marginal $)=0.30$} \\
\hline \multicolumn{4}{|l|}{$\mathrm{R}^{2}($ conditional $)=0.30$} \\
\hline \multicolumn{4}{|c|}{ sniff pedal marks (all classes of individuals except cubs) } \\
\hline (intercept) & -2.069 & 0.797 & 0.009 \\
\hline days_pedal & -0.725 & 0.389 & 0.062 \\
\hline Prec_pedal & -0.013 & 0.006 & 0.036 \\
\hline Temp_pedal & -0.011 & 0.005 & 0.013 \\
\hline season & 2.046 & 0.546 & $<0.001$ \\
\hline \multicolumn{4}{|l|}{$\mathrm{R}^{2}($ marginal $)=0.21$} \\
\hline \multicolumn{4}{|l|}{$\mathrm{R}^{2}($ conditional $)=0.26$} \\
\hline \multicolumn{4}{|l|}{ pedal marking (males) } \\
\hline (intercept) & 1.946 & 0.494 & $<0.0001$ \\
\hline days_pedal & -1.255 & 0.477 & 0.009 \\
\hline tree_rubbing & 1.315 & 0.527 & 0.013 \\
\hline \multicolumn{4}{|l|}{$\mathrm{R}^{2}($ marginal $)=0.20$} \\
\hline \multicolumn{4}{|c|}{$\mathrm{R}^{2}($ conditional $)=0.20$} \\
\hline \multicolumn{4}{|c|}{ sniff tree (all classes of individuals except cubs) } \\
\hline (intercept) & -0.090 & 0.249 & 0.717 \\
\hline days & 0.885 & 0.379 & 0.019 \\
\hline Prec_tree & -0.011 & 0.005 & 0.047 \\
\hline \multicolumn{4}{|l|}{$\mathrm{R}^{2}($ marginal $)=0.06$} \\
\hline \multicolumn{4}{|l|}{$\mathrm{R}^{2}($ conditional $)=0.06$} \\
\hline \multicolumn{4}{|c|}{ tree rubbing (all classes of individuals except cubs) } \\
\hline (intercept) & -3.611 & 0.651 & $<0.0001$ \\
\hline days_tree & 0.857 & 0.461 & 0.063 \\
\hline sniff_tree & 1.412 & 0.352 & $<0.0001$ \\
\hline pedal_marking & 1.293 & 0.502 & 0.010 \\
\hline \multicolumn{4}{|l|}{ age_sex } \\
\hline Undetermined & 0.378 & 0.771 & 0.624 \\
\hline
\end{tabular}




\begin{tabular}{rrrr} 
Juvenile & 1.790 & 0.753 & 0.018 \\
Male & 1.146 & 0.666 & 0.086 \\
$\mathrm{R}^{2}($ marginal $)=0.36$ & & & \\
$\mathrm{R}^{2}($ conditional $)=0.37$ & & & \\
\hline
\end{tabular}

7

8 
Figure 1

Monthly distribution of brown bear visits to the marking site

The average number of individual visits per day of sampling (left axis, indicating the total number and those identified as males) and the sampling effort (right axis), measured as the proportion of days that the camera trap was active every month (x-axis) between April 2012 and December 2015. See Table S1 in Supplementary material for numerical data.

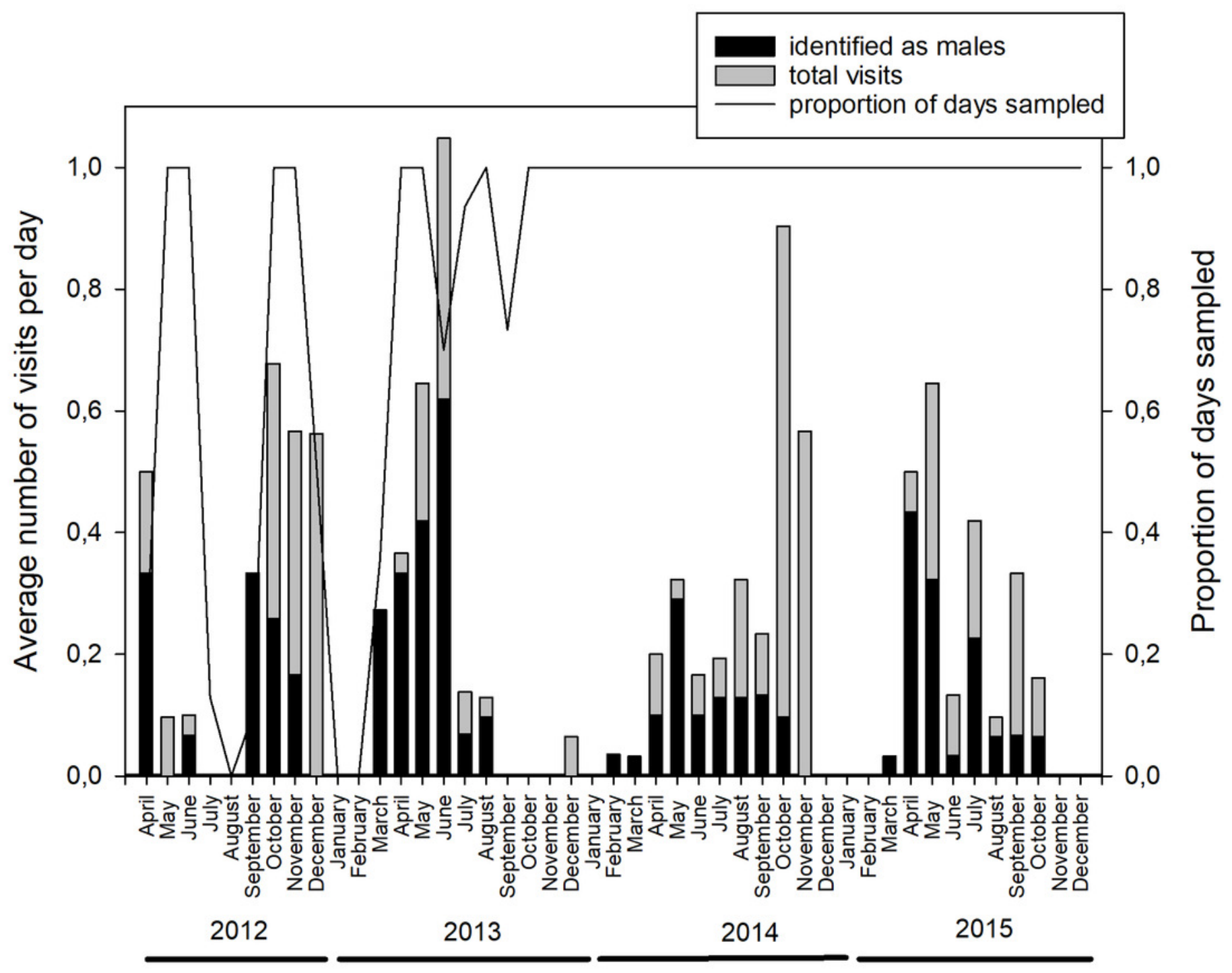


Figure 2

Proportion of the different behaviors

Proportion of all observed behaviors performed by age and sex classes (panels A and B) and per month (panels $C$ and D). Proportions were calculated as the number of observations within each class divided by the total number of observations of all behaviors in all size classes. Data in Tables S4 and S5. 

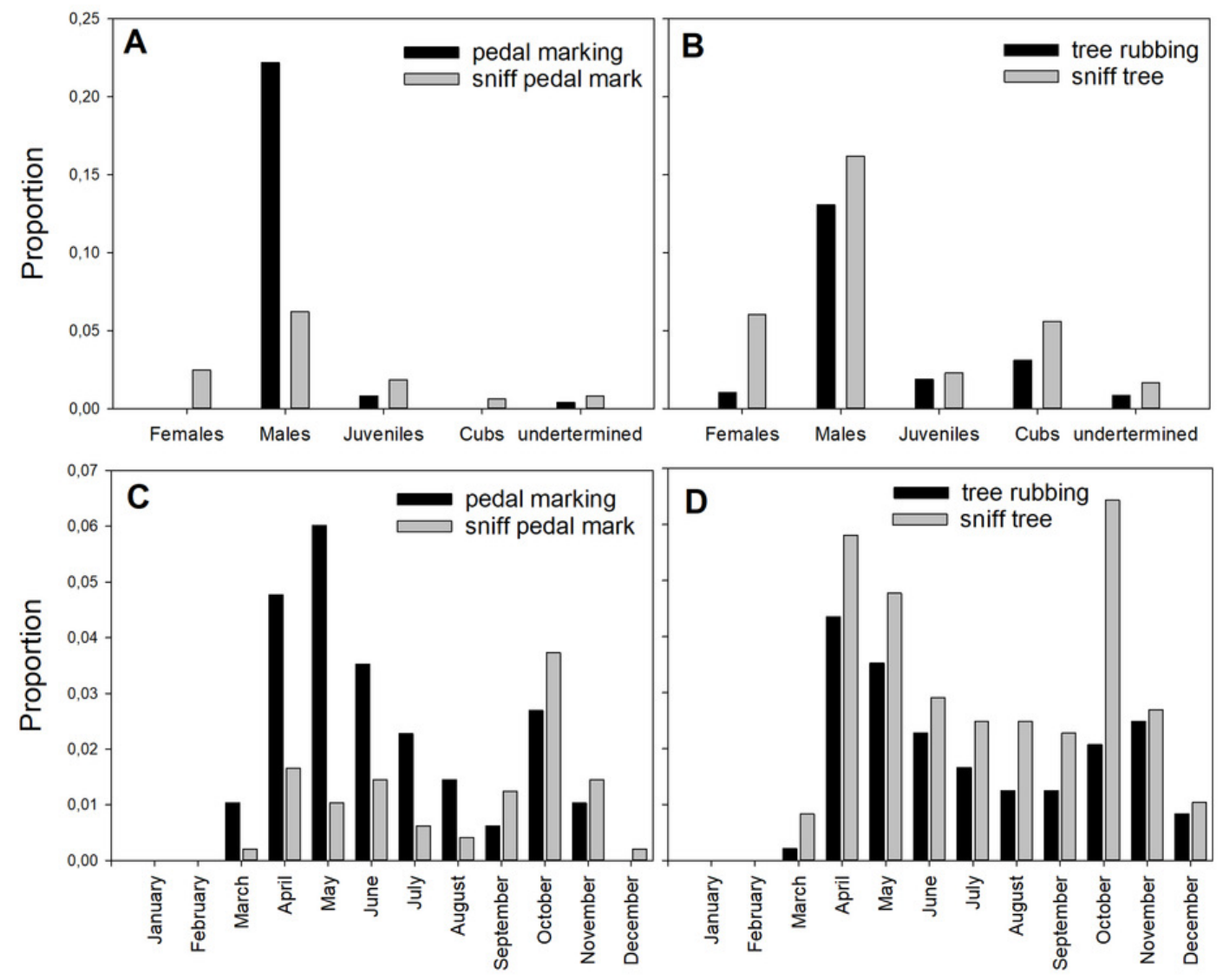